\title{
Power and Thermal Efficiency Optimization of an Irreversible Steady-Flow Lenoir Cycle
}

\author{
Ruibo Wang ${ }^{1,2}$, Yanlin Ge ${ }^{1,2}$, Lingen Chen ${ }^{1,2, * \mathbb{D}}$, Huijun Feng ${ }^{1,2}$ and Zhixiang $\mathrm{Wu}^{1,2}$ \\ 1 Institute of Thermal Science and Power Engineering, Wuhan Institute of Technology, Wuhan 430205, China; \\ ruibowq@126.com (R.W.); geyali9@hotmail.com (Y.G.); huijunfeng@139.com (H.F.); \\ zhixiangwuhg@outlook.com (Z.W.) \\ 2 School of Mechanical \& Electrical Engineering, Wuhan Institute of Technology, Wuhan 430205, China \\ * Correspondence: lgchenna@yahoo.com
}

check for updates

Citation: Wang, R.; Ge, Y.; Chen, L.; Feng, H.; Wu, Z. Power and Thermal Efficiency Optimization of an Irreversible Steady-Flow Lenoir Cycle. Entropy 2021, 23, 425. https://doi.org/10.3390/e23040425

Academic Editor: Michel Feidt

Received: 15 March 2021

Accepted: 31 March 2021

Published: 2 April 2021

Publisher's Note: MDPI stays neutral with regard to jurisdictional claims in published maps and institutional affiliations.

Copyright: (c) 2021 by the authors. Licensee MDPI, Basel, Switzerland. This article is an open access article distributed under the terms and conditions of the Creative Commons Attribution (CC BY) license (https:// creativecommons.org/licenses/by/ $4.0 /)$.

\begin{abstract}
Using finite time thermodynamic theory, an irreversible steady-flow Lenoir cycle model is established, and expressions of power output and thermal efficiency for the model are derived. Through numerical calculations, with the different fixed total heat conductances $\left(U_{T}\right)$ of two heat exchangers, the maximum powers $\left(P_{\max }\right)$, the maximum thermal efficiencies $\left(\eta_{\max }\right)$, and the corresponding optimal heat conductance distribution ratios $\left(u_{L_{P}(o p t)}\right)$ and $\left(u_{L_{\eta}(o p t)}\right)$ are obtained. The effects of the internal irreversibility are analyzed. The results show that, when the heat conductances of the hot- and cold-side heat exchangers are constants, the corresponding power output and thermal efficiency are constant values. When the heat source temperature ratio $(\tau)$ and the effectivenesses of the heat exchangers increase, the corresponding power output and thermal efficiency increase. When the heat conductance distributions are the optimal values, the characteristic relationships of $P-u_{L}$ and $\eta-u_{L}$ are parabolic-like ones. When $U_{T}$ is given, with the increase in $\tau$, the $P_{\max }, \eta_{\max }, u_{L_{P}(o p t)}$, and $u_{L_{\eta}(o p t)}$ increase. When $\tau$ is given, with the increase in $U_{T}, P_{\max }$ and $\eta_{\max }$ increase, while $u_{L_{P}}(o p t)$ and $u_{L_{\eta}(o p t)}$ decrease.
\end{abstract}

Keywords: finite time thermodynamics; irreversible Lenoir cycle; cycle power; thermal efficiency; heat conductance distribution; performance optimization

\section{Introduction}

Finite time thermodynamic (FTT) theory [1-4] has been applied to the performance analysis and optimization of heat engine (HEG) cycles, and fruitful results have been achieved for both reciprocating and steady-flow cycle models. For the steady-flow models, FTT was also termed as finite physical dimensions thermodynamics by Feidt [5-10]. The famous thermal efficiency formula $\eta=1-\sqrt{T_{L} / T_{H}}$, where $T_{H}$ and $T_{L}$ are the temperatures of the heat source and heat sink of a HEG, was derived by Moutier [11] in 1872, Cotterill [12] in 1890, and Novikov [13] and Chambadel [14] in 1957 for steady-flow power plants, while the systematical analysis combining thermodynamics with heat transfer for Carnot cycle was performed by Curzon and Ahlborn [15] in 1975 for reciprocating model, and FTT development was promoted by Berry's group [4].

A large number of works have been performed for reciprocating (finite time) models [16-25] by applying FTT. While finite size is the major feature for steady-flow devices, such as closed gas rubine (Brayton cycle) power plants and steam (Rankine cycle) and organic Rankine cycle power plants, many scholars have performed FTT studies for various steady-flow cycles with the power output (POW), thermal efficiency (TEF), exergy efficiency, profit rate, and ecological function as the optimization goals, under the conditions of different losses and heat transfer laws [26-51].

Lenoir [52] first proposed the Lenoir cycle (LC) model in 1860. The simple LC consists of only three processes of constant-volume endothermic, adiabatic expansion, and constantpressure exothermic; the LC is also called the triangular cycle. According to the cycle 
form, LC can be divided into steady-flow and reciprocating. Georgiou [53] first used classical thermodynamics to study the performances of simple, regenerated, and modified regenerated steady-flow Lenoir cycles (SFLCs).

Following on from [53], Shen et al. [54] applied FTT theory to optimize the POW and TEF characteristics of the endoreversible SFLC with only the loss of heat resistance, and they studied the influences of heat source temperature ratio and total heat conductance (HC) on cycle performance. Ahmadi et al. [55] used a genetic algorithm to carry out multiobjective optimization for endoreversible SFLC, and they obtained the optimal values of ecological performance coefficient and thermal economy under different temperature ratios.

In this paper, an irreversible SFLC model will be established on the basis of [54], while the cycle performance will be analyzed and optimized with the POW and TEF as objective functions, the optimal HC distributions of hot- and cold-side heat exchangers (HACHEX) of the cycle will be studied under different fixed total HCs, and the characteristic relationships between POW and TEF versus HC distribution are obtained. The effect of the internal irreversibility will be analyzed.

\section{Cycle Model}

Figures 1 and 2 show the $T-s$ and $p-v$ diagrams of the irreversible SFLC. As can be seen, $1 \rightarrow 2$ is the constant-volume endothermic process, $2 \rightarrow 3$ is the irreversible adiabatic expansion process ( $2 \rightarrow 3 S$ is the corresponding isentropic process), and $3 \rightarrow 1$ is the constant-pressure exothermic process. Assuming the cycle WF is an ideal gas, the entire cycle needs to be completed between the heat source $\left(T_{H}\right)$ and heat $\operatorname{sink}\left(T_{L}\right)$.



Figure 1. $T-s$ diagram for the irreversible steady-flow Lenoir cycle (SFLC).

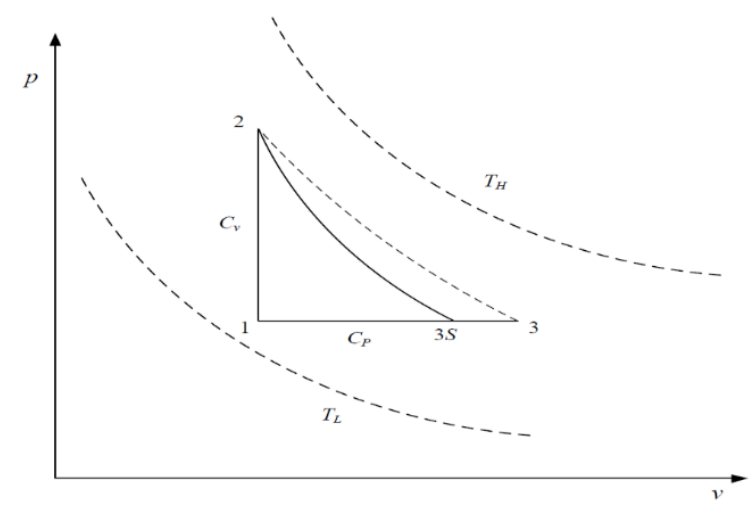

Figure 2. $p-v$ diagram for the irreversible SFLC. 
In the actual work of the HEG, there are irreversible losses during compression and expansion processes; thus, the irreversible expansion efficiency $\eta_{E}$ is defined to describe the irreversible loss during the expansion process.

$$
\eta_{E}=\frac{T_{2}-T_{3}}{T_{2}-T_{3 S}}
$$

where $T_{i}(i=2,3,3 S)$ is the corresponding state point temperature.

Assuming that the heat transfer between the WF and heat reservoir obeys the law of Newton heat transfer, according to the theory of the heat exchanger (HEX) and the ideal gas properties, the cycle heat absorbing and heat releasing rates are, respectively,

$$
\begin{aligned}
& \dot{Q}_{1 \rightarrow 2}=\dot{m} C_{v} E_{H}\left(T_{H}-T_{1}\right)=\dot{m} C_{v}\left(T_{2}-T_{1}\right), \\
& \dot{Q}_{3 \rightarrow 1}=\dot{m} C_{P} E_{L}\left(T_{3}-T_{L}\right)=\dot{m} C_{P}\left(T_{3}-T_{1}\right),
\end{aligned}
$$

where $\dot{m}$ is the mass flow rate of the $\mathrm{WF}, C_{v}\left(C_{P}\right)$ is the constant-volume (constant-pressure) $\mathrm{SH}\left(C_{P}=k C_{v}, k\right.$ is the cycle $\mathrm{SH}$ ratio), and $E_{H}\left(E_{L}\right)$ is the effectiveness of hot-side (cold-side) HEX.

The relationships among the effectivenesses with the corresponding heat transfer unit numbers $\left(N_{H}, N_{L}\right)$ and HCs $\left(U_{H}, U_{L}\right)$ are as follows:

$$
\begin{gathered}
N_{H}=U_{H} /\left(\dot{m} C_{v}\right), \\
N_{L}=U_{L} /\left(\dot{m} k C_{v}\right), \\
E_{H}=1-\exp \left(-N_{H}\right), \\
E_{L}=1-\exp \left(-N_{L}\right) .
\end{gathered}
$$

\section{Analysis and Discussion}

\subsection{Power and Thermal Efficiency Expressions}

According to the second law of thermodynamics, after a cycle process, the total entropy change of the WF is equal to zero; thus, one finds

$$
C_{v} \ln \left(T_{2} / T_{1}\right)-C_{P} \ln \left(T_{3 S} / T_{1}\right)=0 .
$$

From Equation (8), one obtains

$$
\frac{T_{2}}{T_{1}}=\left(\frac{T_{3 S}}{T_{1}}\right)^{k} .
$$

From Equations (2) and (3), one has

$$
\begin{gathered}
T_{2}=E_{H}\left(T_{H}-T_{1}\right)+T_{1}, \\
T_{3}=\left(E_{L} T_{L}-T_{1}\right) /\left(E_{L}-1\right) .
\end{gathered}
$$

Combining Equations (1), (9), and (10) with Equation (11) yields

$$
T_{1}=\frac{E_{H} T_{H}\left(\eta_{E}-1\right)+\left(T_{1}-E_{L} T_{L}\right) /\left(1-E_{L}\right)}{\left\{\left(1-E_{H}\right)\left(1-\eta_{E}\right)+\left\{\left[E_{H} T_{H}+\left(1-E_{H}\right) T_{1}\right] / T_{1}\right\}^{\frac{1}{k}} \eta_{E}\right\}} .
$$

From Equations (2), (3) and (9)-(11), the POW and TEF expressions of the irreversible SFLC can be obtained as

$$
P=\dot{Q}_{1 \rightarrow 2}-\dot{Q}_{3 \rightarrow 1}=\dot{m} C_{v}\left[E_{H}\left(T_{H}-T_{1}\right)-\frac{k E_{L}\left(T_{1}-T_{L}\right)}{1-E_{L}}\right],
$$




$$
\eta=P / \dot{Q}_{1 \rightarrow 2}=1-\frac{k E_{L}\left(T_{1}-T_{L}\right)}{E_{H}\left(1-E_{L}\right)\left(T_{H}-T_{1}\right)} .
$$

When $\eta_{E}=1$, Equation (12) simplifies to

$$
T_{1}-E_{L} T_{L}=\left(1-E_{L}\right)\left[E_{H} T_{H}+\left(1-E_{H}\right) T_{1}\right]^{\frac{1}{k}} T_{1}^{1-\frac{1}{k}} .
$$

Equation (15) in this paper is consistent with Equation (15) in [54], where $T_{1}$ was obtained for the endoreversible SFLC. Combining Equations (13)-(15) and using the numerical solution method, the POW and TEF characteristics of the endoreversible SFLC in [54] can be obtained.

\subsection{Case with Given Hot- and Cold-Side HCs}

The working cycles of common four-branch HEGs, such as Carnot, Brayton, and Otto engines, can be roughly divided into four processes: compression, endothermic, expansion, and exothermic. Compared with these common four-stroke cycles, the biggest feature of the SFLC is the lack of a gas compression process, presenting a relatively rare three-branch cycle model.

When the hot- and cold-side HCs are constant, it can be seen from Equations (4)-(7) that the effectivenesses of the HACHEX which are directly related to each cycle state point temperature will be fixed values; as a result, the POW and TEF will also be fixed values.

\subsection{Case with Variable Hot- and Cold-Side HCs When Total HC Is Given}

When the HC changes, the POW and TEF of the cycle will also change; therefore, the HC can be optimized and the optimal POW and TEF can be obtained. Assuming the total $\mathrm{HC}$ is a constant,

$$
U_{L}+U_{H}=U_{T}
$$

Defining the HC distribution ratio as $u_{L}=\frac{U_{L}}{U_{T}}\left(0<u_{L}<1\right)$, from Equations (4)-(7), the effectivenesses of the HACHEX can be represented as

$$
\begin{gathered}
E_{H}=1-\exp \left[-\left(1-u_{L}\right) U_{T} /\left(\dot{m} C_{v}\right)\right], \\
E_{L}=1-\exp \left[-u_{L} U_{T} /\left(\dot{m} k C_{v}\right)\right] .
\end{gathered}
$$

Combining Equations (12)-(14) and (17) with Equation (18) and using a numerical solution method, the characteristic relationships between POW and the hot- and cold-side HC distribution ratio, as well as between TEF and the hot- and cold-side HC distribution ratio, can be obtained.

\section{Numerical Examples}

It is assumed that the working fluid is air. Therefore, its constant-volume specific heat and specific heat ratio are $C_{v}=0.7165 \mathrm{~kJ} /(\mathrm{kg} \cdot \mathrm{K})$ and $k=1.4$. The turbine efficiency of the gas turbine is about $\eta_{E}=0.92$ in general. According to the [51-55], $\dot{m}=1.1165 \mathrm{~kg} / \mathrm{s}$ and $T_{L}=320 \mathrm{~K}$ were set.

Figure 3 shows the POW and TEF characteristics when the HCs of the HACHEX and temperature ratio are different values. When the HCs and temperature ratio are fixed values, the effectivenesses of the HEX are fixed values, and the corresponding POW and TEF are also fixed values. The POW and TEF characteristics are reflected in the graph as a point. As can be seen, when $\tau\left(\tau=T_{H} / T_{L}\right)$ and the HCs of the HEXs increase, the corresponding POW and TEF increase. Figure 4 shows the influence of $\eta_{E}$ on $P-\eta$ characteristics when the HCs of HACHEX and temperature ratio are given. As can be seen, with the increase in $\eta_{E}$ (the decrease of irreversible loss), the corresponding $P$ and $\eta$ increase. 


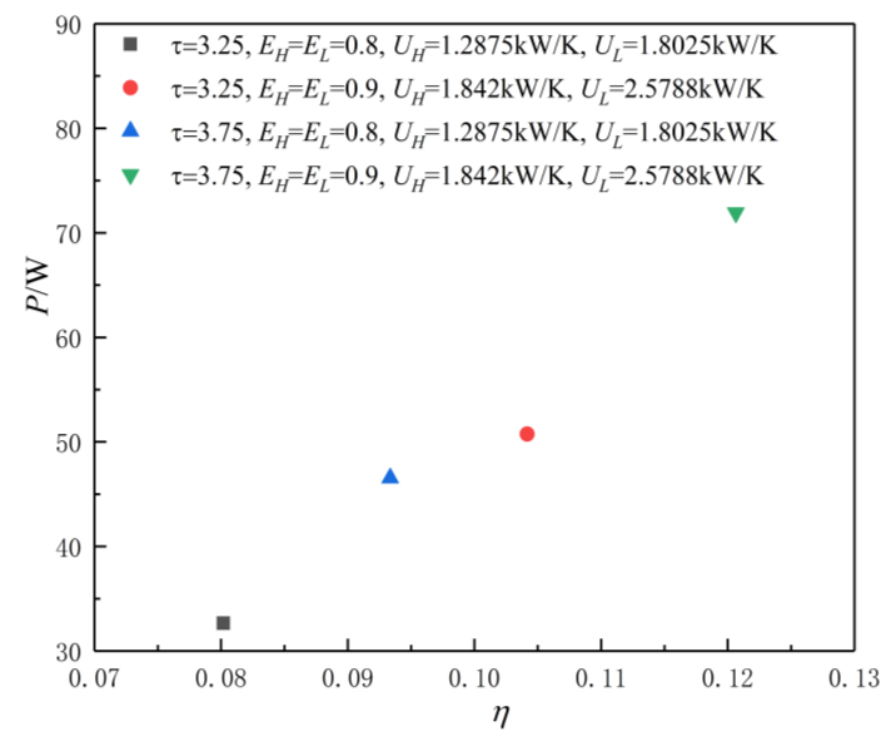

Figure 3. The power output (POW) and thermal efficiency (TEF) characteristics when the HCs of HACHEX are given.

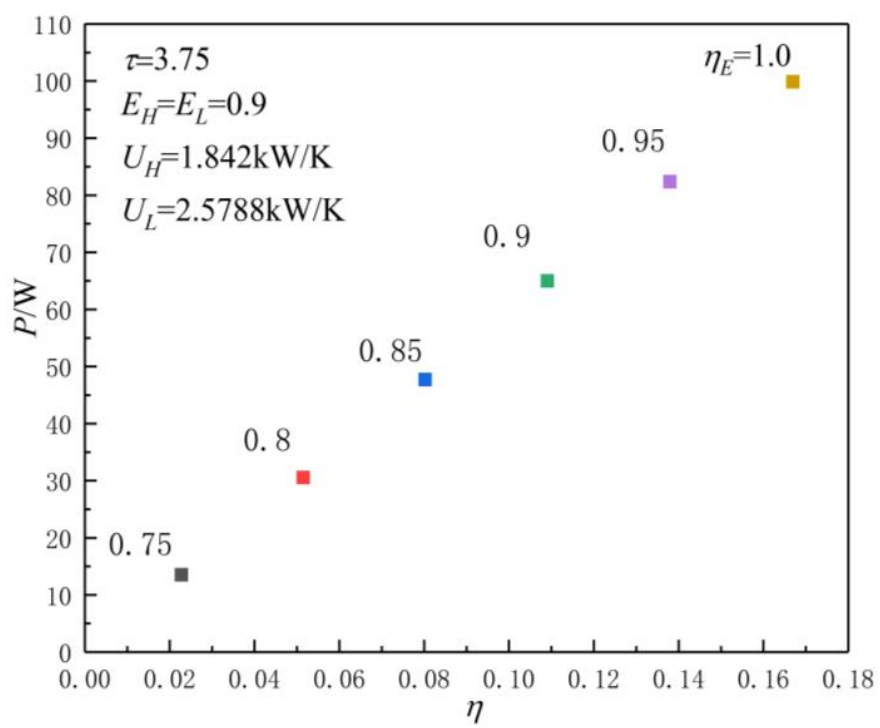

Figure 4. Effect of $\eta_{E}$ on $P-\eta$ characteristics when the HCs of HACHEX are given.

Figures 5-8 show the influences of $U_{T}$ on the $P-u_{L}$ and $\eta-u_{L}$ characteristics when $\tau=3.25$ and $\tau=3.75$. The relationship curves of $P-u_{L}$ and $\eta-u_{L}$ are parabolic-like changes. With the increase in $u_{L}$, the corresponding POW and TEF first increase and then decrease, and there are optimal HC distribution values $u_{L_{P}(o p t)}$ and $u_{L_{\eta}(o p t)}$, which lead to POW and TEF reaching their maximum values $P_{\max }$ and $\eta_{\max }$.

Figures 5 and 6 show the influence of $U_{T}$ on $P-u_{L}$ characteristics when $\tau=3.25$ and $\tau=3.75$. As can be seen, with the increase in $U_{T}, P_{\max }$ increases and $u_{L_{P}(o p t)}$ decreases. When $U_{T}$ is $2.5,5,7.5$, and $10 \mathrm{~kW} / \mathrm{K}$ and $\tau=3.25$, the corresponding $P_{\max }$ is $23.04,56.58$, 70.25 , and $74.39 \mathrm{~W}$, while $u_{L_{P}(o p t)}$ is $0.58,0.575,0.574$, and 0.573 , respectively. When $U_{T}$ changes from 2.5 to $10 \mathrm{~kW} / \mathrm{K}$, the corresponding $P_{\max }$ increases by about $222.9 \%$, while the $u_{L_{P}(o p t)}$ decreases by about $1.21 \%$. When $U_{T}$ is $2.5,5,7.5$, and $10 \mathrm{~kW} / \mathrm{K}$ and $\tau=3.75$, the corresponding $P_{\max }$ is $33.06,80.06,90.24$, and $105.06 \mathrm{~W}$, while $u_{L_{P}(o p t)}$ is $0.586,0.579,0.5785$, and 0.5782 , respectively. When $U_{T}$ changes from 2.5 to $10 \mathrm{~kW} / \mathrm{K}$, the corresponding $P_{\max }$ increases by about $217.8 \%$, while the $u_{L_{P}(o p t)}$ decreases by about $1.33 \%$. 
Figures 7 and 8 show the influence of $U_{T}$ on $\eta-u_{L}$ characteristics when $\tau=3.25$ and $\tau=3.75$. As can be seen, with the increase in $U_{T}, \eta_{\max }$ increases and $u_{L_{\eta}(o p t)}$ decreases. When $U_{T}$ is $2.5,5,7.5$, and $10 \mathrm{~kW} / \mathrm{K}$ and $\tau=3.25$, the corresponding $\eta_{\max }$ is $0.066,0.111$, 0.126 , and 0.1303 , while $u_{L \eta}$ (opt) is $0.629,0.614,0.605$, and 0.6 , respectively. When $U_{T}$ changes from 2.5 to $10 \mathrm{~kW} / \mathrm{K}$, the corresponding $\eta_{\max }$ increases by about $97.4 \%$, while $u_{L_{P}(o p t)}$ decreases by about $4.61 \%$. When $U_{T}$ is $2.5,5,7.5$, and $10 \mathrm{~kW} / \mathrm{K}$ and $\tau=3.75$, the corresponding $\eta_{\max }$ is $0.0774,0.129,0.1458$, and 0.1506 , while $u_{L_{\eta}(o p t)}$ is $0.644,0.624,0.608$, and 0.606 , respectively. When $U_{T}$ changes from 2.5 to $10 \mathrm{~kW} / \mathrm{K}$, the corresponding $\eta_{\max }$ increases by about $94.6 \%$, while $u_{L_{P}(o p t)}$ decreases by about $5.9 \%$.

From Figures 5-8 and Equations (12)-(14), (17), and (18), one can see that, when $\tau$ is given, the POW and TEF are mainly affected by the total HC; with the increase in $U_{T}$, the $P_{\max }$ and $\eta_{\max }$ increase. When the total $\mathrm{HC}$ is small, the corresponding $P_{\max }$ and $\eta_{\max }$ change more significantly. When the total HC is large, the corresponding $P_{\max }$ and $\eta_{\max }$ change little. When $U_{T}$ is given, with the increase in $\tau$, the $u_{L_{p}(o p t)}$ and $u_{L_{\eta}(o p t)}$ increase. When $\tau$ and $U_{T}$ are given, the corresponding $u_{L_{\eta}(o p t)}>u_{L_{P}(o p t)}$.

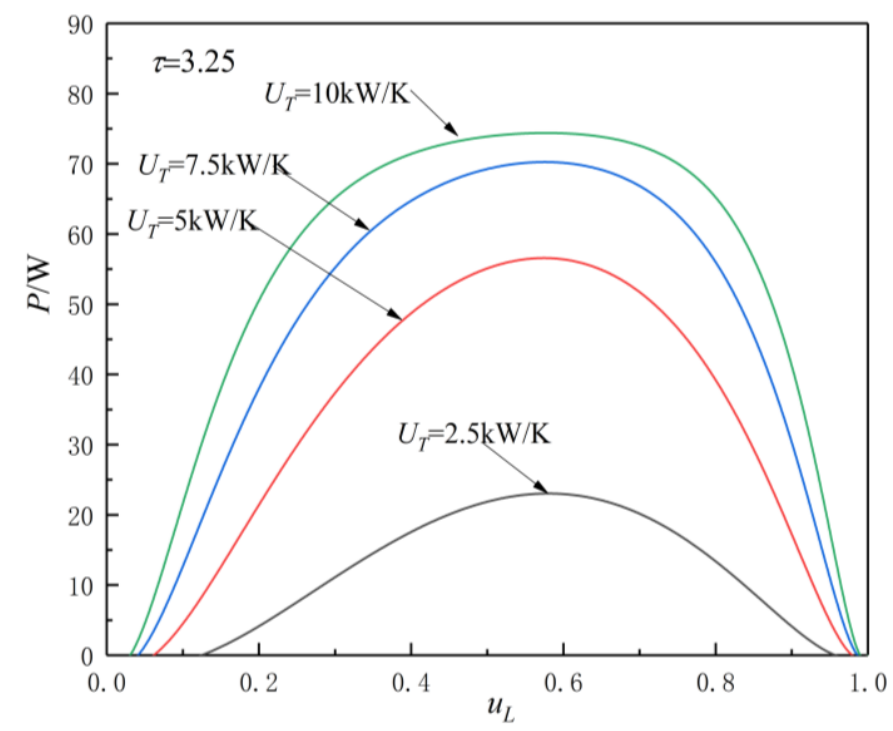

Figure 5. Effect of $U_{T}$ on $P-u_{L}$ characteristics when $\tau=3.25$.

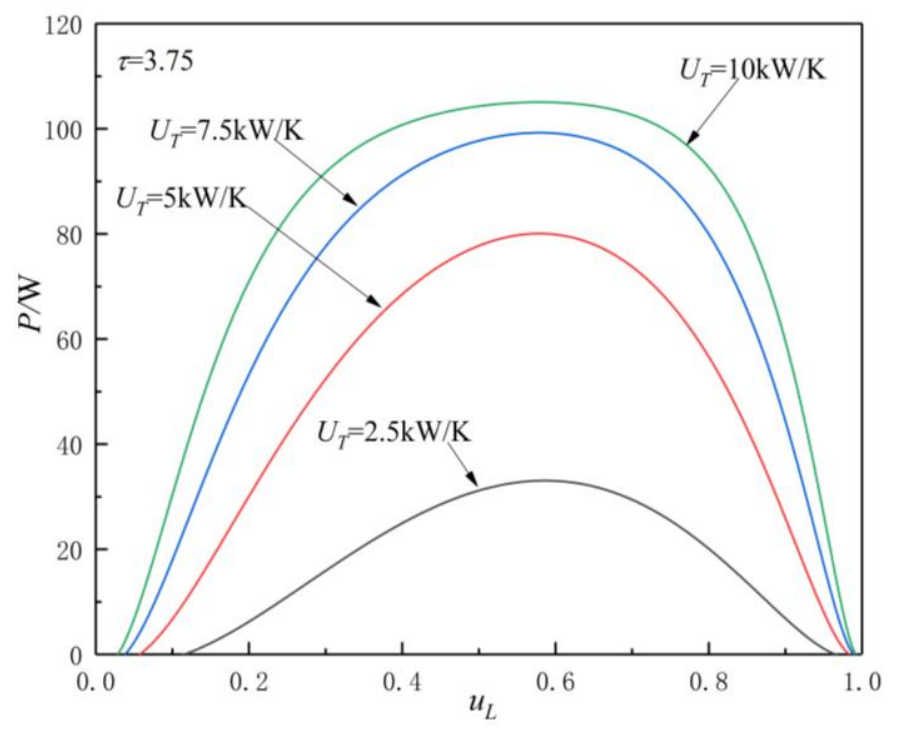

Figure 6. Effect of $U_{T}$ on $P-u_{L}$ characteristics when $\tau=3.75$. 




Figure 7. Effect of $U_{T}$ on $\eta-u_{L}$ characteristics when $\tau=3.25$.

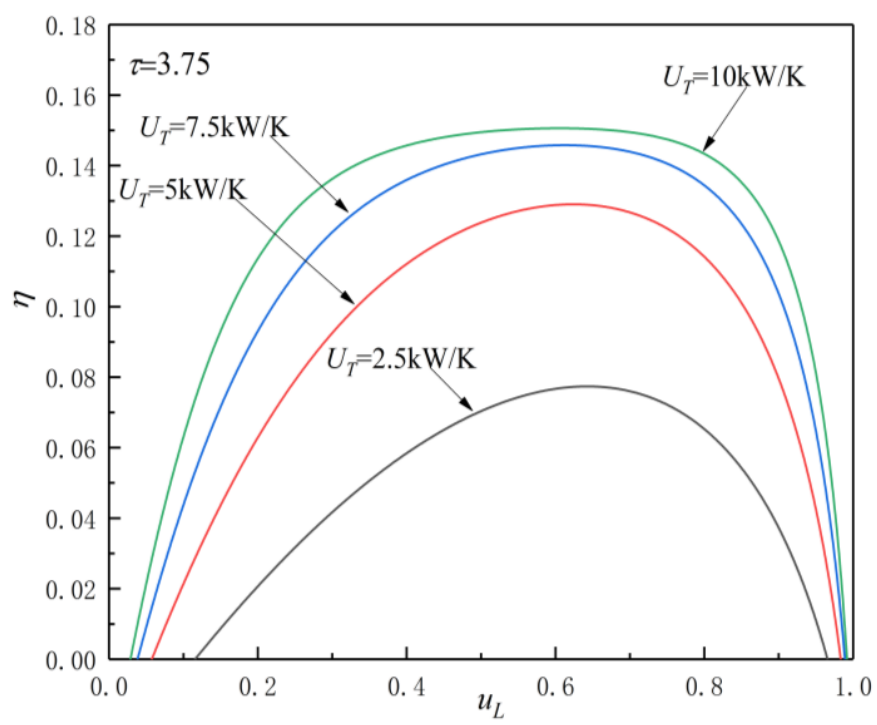

Figure 8. Effect of $U_{T}$ on $\eta-u_{L}$ characteristics when $\tau=3.75$.

Figures 9 and 10 show the influences of $\eta_{E}$ on $P-u_{L}$ and $\eta-u_{L}$ characteristics when $\tau=3.75$ and $U_{T}=7.5 \mathrm{~kW} / \mathrm{K}$. As can be seen, when $\tau=3.75$ and $U_{T}=7.5 \mathrm{~kW} / \mathrm{K}$, with the increase in $\eta_{E}$ (the decrease in irreversible loss), the $P_{\max }$ and $\eta_{\max }$ increase, while the corresponding $u_{L_{P}(o p t)}$ and $u_{L_{\eta}(o p t)}$ decrease. When $\eta_{E}$ is $0.75,0.8,0.85,0.9,0.95$, and 1.0, the corresponding $P_{\max }$ is $30.2431,50.4808,70.7674,91.0982,111.4719$, and $131.8876, \eta_{\max }$ is $0.0445,0.0743,0.1041,0.1339,0.1637$, and $0.1935, u_{L_{P}(o p t)}$ is $0.601,0.593,0.586,0.581,0.576$, and 0.572 , and $u_{L_{\eta}(o p t)}$ is $0.619,0.617,0.615,0.613,0.611$, and 0.609 , respectively. When $\eta_{E}$ changes from 0.75 to 1.0 , the corresponding $P_{\max }$ increases by about $336.1 \%, \eta_{\max }$ increases by about $334.8 \%, u_{L_{P}(o p t)}$, and $u_{L_{\eta}(o p t)}$ decreases by about $4.83 \%$ and $1.62 \%$, respectively. 


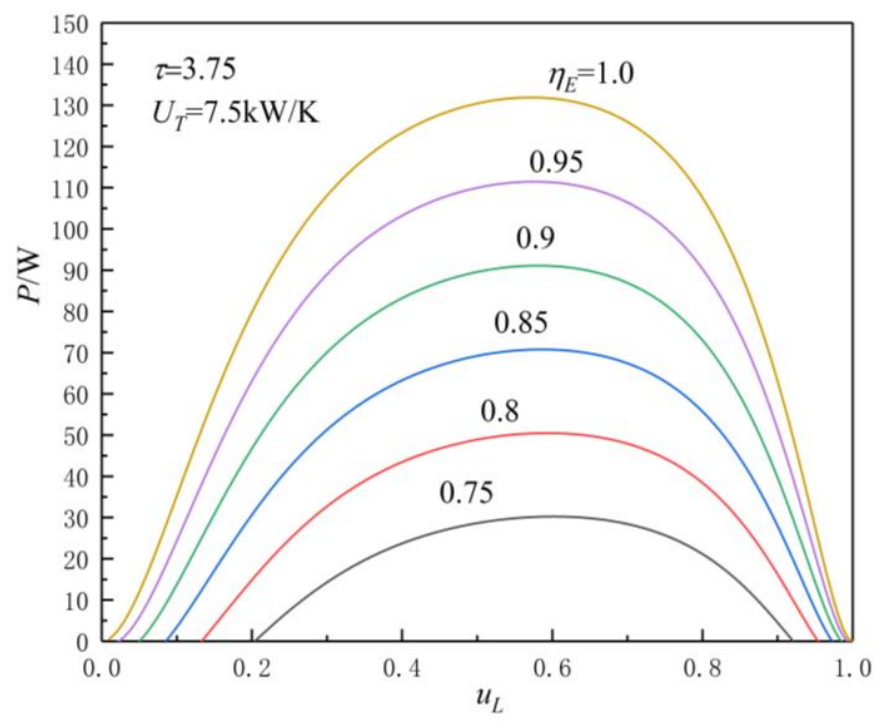

Figure 9. Effect of $\eta_{E}$ on $P-u_{L}$ characteristics.

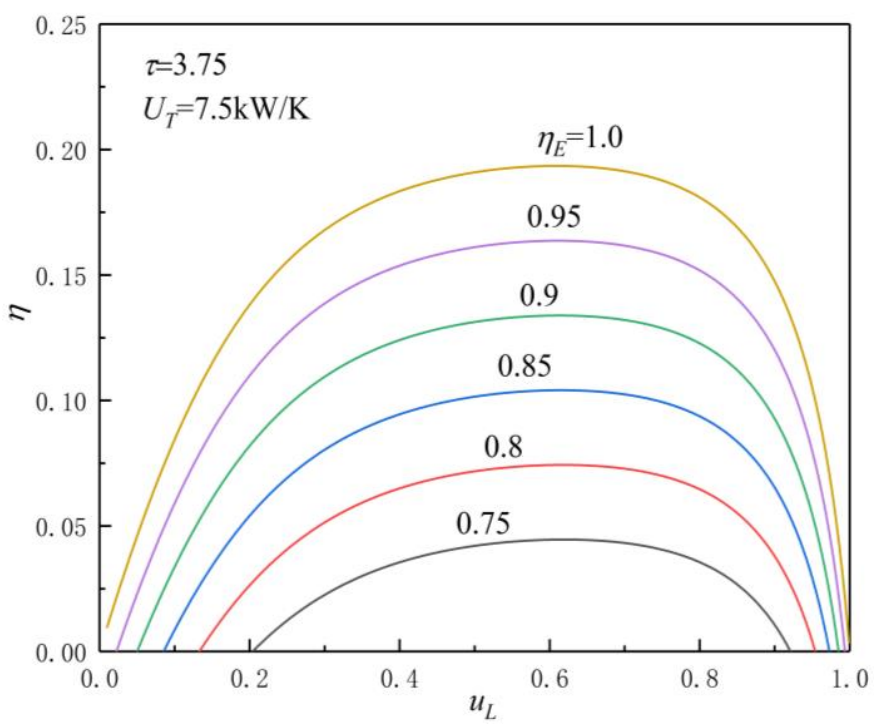

Figure 10. Effect of $\eta_{E}$ on $\eta-u_{L}$ characteristics.

\section{Conclusions}

In this paper, an irreversible SFLC model is established on the basis of [54], while the POW and TEF characteristics of the irreversible SFLC were studied using FTT theory, and the influences of $\tau, U_{T}$ and $\eta_{E}$ on $P_{\max }, \eta_{\max }, u_{L_{P}(o p t)}$, and $u_{L_{\eta}(o p t)}$ were analyzed. The main conclusions are as follows:

(1) When the HCs are constants, the corresponding POW and TEF are fixed values. When $\tau$ and the HCs of the HEXs increase, the corresponding POW and TEF increase. When $\tau$ and HCs of the HEXs are constants, with the increase in $\eta_{E}$ (the decrease in irreversible loss), the corresponding $P$ and $\eta$ increase.

(2) When the distribution of HCs can be optimized, the relationships of $P-u_{L}$ and $\eta-u_{L}$ are parabolic-like ones.

(3) When $U_{T}$ is given, with the increase in $\tau, P_{\max }, \eta_{\max }, u_{L_{P}(o p t)}$, and $u_{L_{\eta}(o p t)}$ increase.

(4) When $\tau$ is given, with the increase in $U_{T}, P_{\max }$ and $\eta_{\max }$ increase, while $u_{L_{P}(o p t)}$ and $u_{L_{\eta}(o p t)}$ decrease. When $\tau$ and $U_{T}$ are given, the corresponding $u_{L_{\eta}(o p t)}$ is bigger than $u_{L_{P}(o p t)}$. 
(5) When $\tau=3.75$ and $U_{T}=7.5 \mathrm{~kW} / \mathrm{K}$, with the increase in $\eta_{E}, P_{\max }$ and $\eta_{\max }$ increase, while the corresponding $u_{L_{P}(o p t)}$ and $u_{L_{\eta}(o p t)}$ decrease.

Author Contributions: Conceptualization, R.W. and L.C.; data curation, Y.G.; funding acquisition, L.C.; methodology, R.W., Y.G., L.C. and H.F.; software, R.W., Y.G., H.F. and Z.W.; supervision, L.C.; validation, R.W., H.F. and Z.W.; writing—original draft preparation, R.W. and Y.G.; writing-reviewing and editing, L.C. All authors have read and agreed to the published version of the manuscript.

Funding: This paper is supported by the National Natural Science Foundation of China (Project No. 51779262).

Acknowledgments: The authors wish to thank the reviewers for their careful, unbiased, and constructive suggestions, which led to this revised manuscript.

Conflicts of Interest: The authors declare no conflict of interest.

\section{Nomenclature}

$\begin{array}{ll}C_{P} & \text { Specific heat at constant pressure }(\mathrm{kJ} /(\mathrm{kg} \cdot \mathrm{K})) \\ C_{v} & \text { Specific heat at constant volume }(\mathrm{kJ} /(\mathrm{kg} \cdot \mathrm{K})) \\ E & \text { Effectiveness of heat exchanger } \\ k & \text { Specific heat ratio }(-) \\ \dot{m} & \text { Mass flow rate of the working fluid }(\mathrm{kg} / \mathrm{s}) \\ N & \text { Number of heat transfer units } \\ P & \text { Cycle power }(\mathrm{W}) \\ \dot{Q} & \text { Quantity of heat transfer rate }(\mathrm{W}) \\ T & \text { Temperature }(\mathrm{K}) \\ U & \text { Heat conductance }(\mathrm{kW} / \mathrm{K}) \\ U_{T} & \text { Total heat conductance }(\mathrm{kW} / \mathrm{K}) \\ u & \text { Heat conductance distribution } \\ \text { Greek symbols } & \\ \tau & \text { Temperature ratio } \\ \eta & \text { Cycle thermal efficiency } \\ \text { Subscripts } & \\ H & \text { Hot-side } \\ L & \text { Cold-side } \\ \text { max } & \text { Maximum value } \\ \text { opt } & \text { Optimal } \\ P & \text { Maximum power point } \\ \eta & \text { Maximum thermal efficiency point } \\ 1-3,3 S & \text { Cycle state points }\end{array}$

\section{Abbreviations}

$\begin{array}{ll}\text { FTT } & \text { Finite time thermodynamic } \\ \text { HACHEX } & \text { Hot- and cold-side heat exchangers } \\ \text { HC } & \text { Heat conductance } \\ \text { HEG } & \text { Heat engine } \\ \text { HEX } & \text { Heat exchanger } \\ \text { LC } & \text { Lenoir cycle } \\ \text { POW } & \text { Power output } \\ \text { SFLC } & \text { Steady flow Lenoir cycle } \\ \text { SH } & \text { Specific heat } \\ \text { TEF } & \text { Thermal efficiency } \\ \text { WF } & \text { Working fluid }\end{array}$

\section{References}

1. Andresen, B.; Berry, R.S.; Ondrechen, M.J. Thermodynamics for processes in finite time. Acc. Chem. Res. 1984, 17, $266-271$. [CrossRef] 
2. Andresen, B. Current trends in finite-time thermodynamics. Angew. Chem. Int. Ed. 2011, 50, 2690-2704. [CrossRef]

3. Feidt, M. The history and perspectives of efficiency at maximum power of the Carnot engine. Entropy 2017, 19, 369. [CrossRef]

4. Berry, R.S.; Salamon, P.; Andresen, B. How it all began. Entropy 2020, 22, 908. [CrossRef] [PubMed]

5. Feidt, M. Finite Physical Dimensions Optimal Thermodynamics 1. Fundamental; ISTE Press and Elsevier: London, UK, 2017.

6. Feidt, M. Finite Physical Dimensions Optimal Thermodynamics 2. Complex. Systems; ISTE Press and Elsevier: London, UK, 2018.

7. Blaise, M.; Feidt, M.; Maillet, D. Influence of the working fluid properties on optimized power of an irreversible finite dimensions Carnot engine. Energy Convers. Manag. 2018, 163, 444-456. [CrossRef]

8. Feidt, M.; Costea, M. From finite time to finite physical dimensions thermodynamics: The Carnot engine and Onsager's relations revisited. J. Non-Equilib. Thermodyn. 2018, 43, 151-162. [CrossRef]

9. Dumitrascu, G.; Feidt, M.; Popescu, A.; Grigorean, S. Endoreversible trigeneration cycle design based on finite physical dimensions thermodynamics. Energies 2019, 12, 3165.

10. Feidt, M.; Costea, M.; Feidt, R.; Danel, Q.; Périlhon, C. New criteria to characterize the waste heat recovery. Energies 2020, 13 , 789. [CrossRef]

11. Moutier, J. Éléments de Thermodynamique; Gautier-Villars: Paris, France, 1872.

12. Cotterill, J.H. Steam Engines, 2nd ed.; E \& F.N. Spon: London, UK, 1890.

13. Novikov, I.I. The efficiency of atomic power stations (A review). J. Nucl. Energy 1957, 7, 125-128. [CrossRef]

14. Chambadal, P. Les Centrales Nucleaires; Armand Colin: Paris, France, 1957; pp. 41-58.

15. Curzon, F.L.; Ahlborn, B. Efficiency of a Carnot engine at maximum power output. Am. J. Phys. 1975, 43, 22-24. [CrossRef]

16. Hoffman, K.H.; Burzler, J.; Fischer, A.; Schaller, M.; Schubert, S. Optimal process paths for endoreversible systems. J. Non-Equilib. Thermodyn. 2003, 28, 233-268. [CrossRef]

17. Zaeva, M.A.; Tsirlin, A.M.; Didina, O.V. Finite time thermodynamics: Realizability domain of heat to work converters. J. Non-Equilib. Thermodyn. 2019, 44, 181-191. [CrossRef]

18. Masser, R.; Hoffmann, K.H. Endoreversible modeling of a hydraulic recuperation system. Entropy 2020, 22, 383. [CrossRef]

19. Masser, R.; Khodja, A.; Scheunert, M.; Schwalbe, K.; Fischer, A.; Paul, R.; Hoffmann, K.H. Optimized piston motion for an alpha-type Stirling engine. Entropy 2020, 22, 700. [CrossRef]

20. Muschik, W.; Hoffmann, K.H. Modeling, simulation, and reconstruction of 2-reservoir heat-to-power processes in finite-time thermodynamics. Entropy 2020, 22, 997. [CrossRef]

21. Andresen, B.; Essex, C. Thermodynamics at very long time and space scales. Entropy 2020, 22, 1090. [CrossRef]

22. Scheunert, M.; Masser, R.; Khodja, A.; Paul, R.; Schwalbe, K.; Fischer, A.; Hoffmann, K.H. Power-optimized sinusoidal piston motion and its performance gain for an Alpha-type Stirling engine with limited regeneration. Energies 2020, 13, 4564. [CrossRef]

23. Chen, L.G.; Feng, H.J.; Ge, Y.L. Maximum energy output chemical pump configuration with an infinite-low- and a finite-highchemical potential mass reservoirs. Energy Convers. Manag. 2020, 223, 113261. [CrossRef]

24. Qi, C.Z.; Ding, Z.M.; Chen, L.G.; Ge, Y.L.; Feng, H.J. Modeling and performance optimization of an irreversible two-stage combined thermal Brownian heat engine. Entropy 2021, 23, 419. [CrossRef]

25. Chen, L.G.; Meng, Z.W.; Ge, Y.L.; Wu, F. Performance analysis and optimization for irreversible combined Carnot heat engine working with ideal quantum gases. Entropy 2021, 23. in press.

26. Bejan, A. Theory of heat transfer-irreversible power plant. Int. J. Heat Mass Transf. 1988, 31, 1211-1219. [CrossRef]

27. Morisaki, T.; Ikegami, Y. Maximum power of a multistage Rankine cycle in low-grade thermal energy conversion. Appl. Therm. Eng. 2014, 69, 78-85. [CrossRef]

28. Sadatsakkak, S.A.; Ahmadi, M.H.; Ahmadi, M.A. Thermodynamic and thermo-economic analysis and optimization of an irreversible regenerative closed Brayton cycle. Energy Convers. Manag. 2015, 94, 124-129. [CrossRef]

29. Yasunaga, T.; Ikegami, Y. Application of finite time thermodynamics for evaluation method of heat engines. Energy Proc. 2017, 129, 995-1001. [CrossRef]

30. Yasunaga, T.; Fontaine, K.; Morisaki, T.; Ikegami, Y. Performance evaluation of heat exchangers for application to ocean thermal energy conversion system. Ocean Therm. Energy Convers. 2017, 22, 65-75.

31. Yasunaga, T.; Noguchi, T.; Morisaki, T.; Ikegami, Y. Basic heat exchanger performance evaluation method on OTEC. J. Mar. Sci. Eng. 2018, 6, 32. [CrossRef]

32. Fontaine, K.; Yasunaga, T.; Ikegami, Y. OTEC maximum net power output using Carnot cycle and application to simplify heat exchanger selection. Entropy 2019, 21, 1143. [CrossRef]

33. Fawal, S.; Kodal, A. Comparative performance analysis of various optimization functions for an irreversible Brayton cycle applicable to turbojet engines. Energy Convers. Manag. 2019, 199, 111976. [CrossRef]

34. Yasunaga, T.; Ikegami, Y. Finite-time thermodynamic model for evaluating heat engines in ocean thermal energy conversion. Entropy 2020, 22, 211. [CrossRef]

35. Yu, X.F.; Wang, C.; Yu, D.R. Minimization of entropy generation of a closed Brayton cycle based precooling-compression system for advanced hypersonic airbreathing engine. Energy Convers. Manag. 2020, 209, 112548. [CrossRef]

36. Arora, R.; Arora, R. Thermodynamic optimization of an irreversible regenerated Brayton heat engine using modified ecological criteria. J. Therm. Eng. 2020, 6, 28-42. [CrossRef]

37. Liu, H.T.; Zhai, R.R.; Patchigolla, K.; Turner, P.; Yang, Y.P. Analysis of integration method in multi-heat-source power generation systems based on finite-time thermodynamics. Energy Convers. Manag. 2020, 220, 113069. [CrossRef] 
38. Gonca, G.; Sahin, B.; Cakir, M. Performance assessment of a modified power generating cycle based on effective ecological power density and performance coefficient. Int. J. Exergy 2020, 33, 153-164. [CrossRef]

39. Karakurt, A.S.; Bashan, V.; Ust, Y. Comparative maximum power density analysis of a supercritical $\mathrm{CO}_{2} \mathrm{Brayton}_{\mathrm{P}}$ power cycle. J. Therm. Eng. 2020, 6, 50-57. [CrossRef]

40. Ahmadi, M.H.; Dehghani, S.; Mohammadi, A.H.; Feidt, M.; Barranco-Jimenez, M.A. Optimal design of a solar driven heat engine based on thermal and thermo-economic criteria. Energy Convers. Manag. 2013, 75, 635-642. [CrossRef]

41. Ahmadi, M.H.; Mohammadi, A.H.; Dehghani, S.; Barranco-Jimenez, M.A. Multi-objective thermodynamic-based optimization of output power of Solar Dish-Stirling engine by implementing an evolutionary algorithm. Energy Convers. Manag. 2013, 75, 438-445. [CrossRef]

42. Ahmadi, M.H.; Ahmadi, M.A.; Mohammadi, A.H.; Feidt, M.; Pourkiaei, S.M. Multi-objective optimization of an irreversible Stirling cryogenic refrigerator cycle. Energy Convers. Manag. 2014, 82, 351-360. [CrossRef]

43. Ahmadi, M.H.; Ahmadi, M.A.; Mehrpooya, M.; Hosseinzade, H.; Feidt, M. Thermodynamic and thermo-economic analysis and optimization of performance of irreversible four-temperature-level absorption refrigeration. Energy Convers. Manag. 2014, 88, 1051-1059. [CrossRef]

44. Ahmadi, M.H.; Ahmadi, M.A. Thermodynamic analysis and optimization of an irreversible Ericsson cryogenic refrigerator cycle. Energy Convers. Manag. 2015, 89, 147-155. [CrossRef]

45. Jokar, M.A.; Ahmadi, M.H.; Sharifpur, M.; Meyer, J.P.; Pourfayaz, F.; Ming, T.Z. Thermodynamic evaluation and multi-objective optimization of molten carbonate fuel cell-supercritical $\mathrm{CO}_{2}$ Brayton cycle hybrid system. Energy Convers. Manag. 2017, 153, 538-556. [CrossRef]

46. Han, Z.H.; Mei, Z.K.; Li, P. Multi-objective optimization and sensitivity analysis of an organic Rankine cycle coupled with a one-dimensional radial-inflow turbine efficiency prediction model. Energy Convers. Manag. 2018, 166, 37-47. [CrossRef]

47. Ghasemkhani, A.; Farahat, S.; Naserian, M.M. Multi-objective optimization and decision making of endoreversible combined cycles with consideration of different heat exchangers by finite time thermodynamics. Energy Convers. Manag. 2018, 171, 1052-1062. [CrossRef]

48. Ahmadi, M.H.; Jokar, M.A.; Ming, T.Z.; Feidt, M.; Pourfayaz, F.; Astaraei, F.R. Multi-objective performance optimization of irreversible molten carbonate fuel cell-Braysson heat engine and thermodynamic analysis with ecological objective approach. Energy 2018, 144, 707-722. [CrossRef]

49. Tierney, M. Minimum exergy destruction from endoreversible and finite-time thermodynamics machines and their concomitant indirect energy. Energy 2020, 197, 117184. [CrossRef]

50. Yang, H.; Yang, C.X. Derivation and comparison of thermodynamic characteristics of endoreversible aircraft environmental control systems. Appl. Therm. Eng. 2020, 180, 115811. [CrossRef]

51. Tang, C.Q.; Chen, L.G.; Feng, H.J.; Ge, Y.L. Four-objective optimization for an irreversible closed modified simple Brayton cycle. Entropy 2021, 23, 282. [CrossRef] [PubMed]

52. Lichty, C. Combustion Engine Processes; McGraw-Hill: New York, NY, USA, 1967.

53. Georgiou, D.P. Useful work and the thermal efficiency in the ideal Lenoir with regenerative preheating. J. Appl. Phys. 2008, 88, 5981-5986. [CrossRef]

54. Shen, X.; Chen, L.G.; Ge, Y.L.; Sun, F.R. Finite-time thermodynamic analysis for endoreversible Lenoir cycle coupled to constanttemperature heat reservoirs. Int. J. Energy Environ. 2017, 8, 272-278.

55. Ahmadi, M.H.; Nazari, M.A.; Feidt, M. Thermodynamic analysis and multi-objective optimisation of endoreversible Lenoir heat engine cycle based on the thermo-economic performance criterion. Int. J. Ambient Energy 2019, 40, 600-609. [CrossRef] 